\title{
Review
}

\section{Aspects of moral character, civic purpose and social identity in relevance to the psychological well-being of adolescents in} Sri Lanka

\author{
Miyuru Chandradasa1, Layani C Rathnayake² \\ ${ }^{1}$ Faculty of Medicine, University of Kelaniya, Sri Lanka, ${ }^{2}$ Psychiatry Unit, District Base Hospital, Dickoya- \\ Hatton, Sri Lanka
}

\section{Keywords: moral development, psychiatry, mental health, spirituality, corporal punishment}

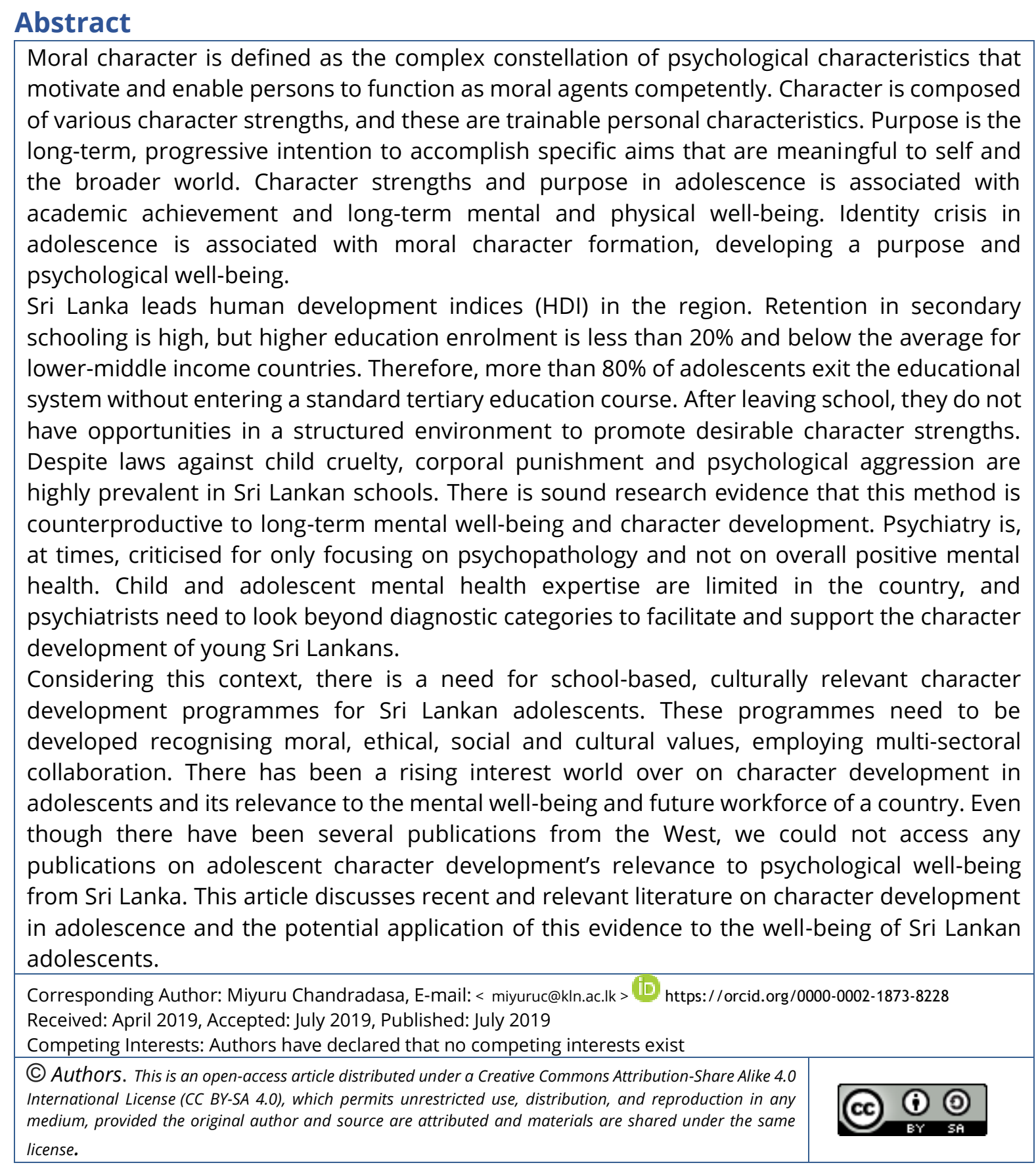




\section{Introduction}

Aristotle described moral character as a harmonious occurrence of thoughts, feelings and actions. He further stated that individuals feel good when they act on rational thought [1]. This ideal state of morality is only achieved only by a few, if any, and only at the highest maturity level of character development. In many adolescents, their character strengths are at different developmental stages and misaligned with each other at a given time [2]. Berkowitz defines moral character as a complex constellation of psychological characteristics that would motivate and enable persons to function as competent moral agents [3]. This refers to the dispositions required for ethical functioning and includes certain qualities such as respect, justice, caring and honesty. On the other hand, another form of the character is described as the performance characteristics, which is built on willing values such as diligence, perseverance and self-discipline.

World Health Organisation defines 'adolescents' as individuals in the 10 to 19 years age category [4]. There is a rising interest world over on character development in adolescents and its relevance to the mental well-being and future workforce of a country. Even though there have been several publications from the West, we could not access any publications on adolescents' character development in relevance to their psychological well-being from Sri Lanka. This article discusses recent and relevant literature on character development and mental well-being in adolescence in Sri Lanka.

\section{Character Strengths}

Many contemporary theorists explain character as a multiplicity that is composed of various character strengths [5]. The most well-developed character strengths are termed signature strengths. It is described that the character strengths of individuals are trainable personal characteristics [6]. There is evidence that emotional, intellectual and interpersonal character strengths are related to better coping with stressful situations at work [6]. The presence of character strengths such as self-regulation, prudence, perseverance and social intelligence is associated with positive teacher-rated classroom behaviour and later school achievement, showing that they have a life-long impact on a person [7]. In adults, character elements like hope, humour and zest are correlated with well-being consistently [8]. These facts emphasise the influence and impact of character strengths to life achievements and why we, as mental health professionals, need to facilitate the growth of desirable character qualities in young people.

\section{Civic Purpose}

Purpose could be defined as a long-term, progressive intention to accomplish specific aims that are important and meaningful to the self and the broader world [9]. Purpose has been categorised as a character strength as it demonstrates connectedness to something more substantial than self. For a young person, a purpose provides direction in life and motivational energy to reach goals [10]. Adolescents with a purpose would connect in meaningful ways with the rest of society through family networks, the belief of justice or religious principles. Adolescents with a fully identified purpose are known to pursue long-term goals, adhere to socially responsible behaviour and make an effort for the betterment of their communities [2]. As a developing nation, Sri Lanka would require the future generations to be socially responsible in achieving long term goals. 
Well-being is a sense of enjoyment and a feeling of happiness in life. Achievement of psychological well-being by the service users should be the goal of a mental health service. The purpose is known to be associated with well-being in life [11]. Civic purpose is related to engagement through civic activity or political action. This is primarily a response in the civic domain through activities such as responsible citizenship, community service, or political participation for the greater good of the society. The underlying moral values related to civic purpose are social responsibility, fairness, human rights, justice and equality [12]. Sri Lankan psychiatric services need to look beyond treating psychopathology only and facilitate this growth in the adolescents of a country. Therefore, child and adolescent mental health services would have to implement schoolbased community services to promote desirable qualities in adolescents.

\section{Identity crisis in adolescence}

According to the well-known scholar Erik Erikson, we experience an identity crisis in adolescence that determine the trajectory of our lives. Erikson described identity as a part of human development across the lifespan with its centrality in adolescence [13]. In the broader psychosocial development theory of Erikson, the fifth stage occurs in the adolescence. With puberty, young people become increasingly concerned about their social roles and how to connect with societal prototypes with their identified skills [14]. As in the West, Sri Lankan adolescent girls are known to value relationships and independence as important themes in their lives [15].

In connection with their social roles, adolescents develop moral values when they reason about societal issues that stir their empathy, such as underlying injustice [12]. These new moral values shape the moral identity of the adolescent parallel to their social connectedness and identity formation. Purpose in an adolescent promotes healthy identity formation and supports a sense of well-being [16]. At school, having a purpose promotes self-regulation and academic achievements as the student finds the work meaningful as part of a long-term goal in life [17]. In all instances, the child and adolescent mental health services would have to support adolescents to continue their schooling.

\section{The Present Context of Sri Lankan Adolescents}

Sri Lanka has a multi-religious population of 21 million with $33 \%$ of that below the age of 19 years. An armed conflict ravaged the nation for almost three decades from the early 1980 s to its end in 2009. Despite facing many atrocities related to the war and several natural disasters including the Boxing Day Tsunami in 2004, the country has achieved the highest rank in Human Development Indices in the South Asian region according to the United Nations Development Programme (UNDP). Development parameters of the country compared to regional counterparts is shown in table 1. 
Table 1: Human development indices for Sri Lanka and selected neighbouring countries

\begin{tabular}{|l|c|c|c|c|c|c|}
\hline Parameter & $\begin{array}{c}\text { Sri } \\
\text { Lanka }\end{array}$ & India & Pakistan & Bangladesh & Thailand & Indonesia \\
\hline $\begin{array}{l}\text { Human Development } \\
\text { Index }\end{array}$ & 0.766 & 0.624 & 0.550 & 0.608 & 0.740 & 0.689 \\
\hline $\begin{array}{l}\text { Human Development } \\
\text { Category }\end{array}$ & High & Medium & Medium & Medium & High & Medium \\
\hline $\begin{array}{l}\text { Adolescent Birth Rate } \\
\text { (births per 1,000 } \\
\text { women ages 15-19) }\end{array}$ & 14.8 & 24.5 & 38.7 & 83.5 & 44.6 & 49.6 \\
\hline $\begin{array}{l}\text { Life expectancy at birth } \\
\text { (years) }\end{array}$ & 75.0 & 68.3 & 66.4 & 72.8 & 74.6 & 69.1 \\
\hline $\begin{array}{l}\text { Maternal Mortality } \\
\text { Rate (deaths per } \\
\text { 100,000 live births) }\end{array}$ & 30 & 174 & 178 & 176 & 20 & 126 \\
\hline $\begin{array}{l}\text { Adult Literacy Rate } \\
\text { above 15 years }\end{array}$ & $92.6 \%$ & $72.1 \%$ & $58.7 \%$ & 72.8 & $96.7 \%$ & $93.9 \%$ \\
\hline $\begin{array}{l}\text { Population with } \\
\text { Secondary Education } \\
\text { above 25 years }\end{array}$ & $80.5 \%$ & $48.7 \%$ & $46.1 \%$ & $45.5 \%$ & $43.3 \%$ & $47.3 \%$ \\
\hline
\end{tabular}

Source: UNDP, 2016

The adolescent birth rate in Sri Lanka is much lower compared to other South Asian countries. Furthermore, a remarkable achievement in Sri Lanka is the high retainability of adolescents in the school system, with more than $80 \%$ of adults having had some secondary education. Tertiary level education is provided mostly by the state sector through 15 universities administered by the University Grants Commission. For the academic year of 2015/2016, out of all state university entrants, $63.2 \%$ were females. Among the entrants to study law, $85.9 \%$ were young women. On the other hand, these educated young women might face psychosocial issues in a patriarchal society where they would be expected to fulfil traditional gender roles [18]. The pathway to higher education among the Sri Lankan adolescents in the year 2014 is shown in Table 2. Further, this table demonstrates the number of adolescents who are leave the education system at each stage.

Table 2: Pathway to Higher Education in Sri Lanka in 2014

\begin{tabular}{|l|l|l|l|l|}
\hline Stage of Education System & Entrants & Passed & Failed & Exits \\
\hline General Certificate of Education - Ordinary Level & $\begin{array}{l}450,000 \\
(100 \%)\end{array}$ & 270,000 & 180,000 & 30,000 \\
\hline $\begin{array}{l}\text { General Certificate of Education - Advanced } \\
\text { Level }\end{array}$ & $240,000(53 \%)$ & 144,000 & 96,000 & 57,000 \\
\hline Higher Education & $\begin{array}{l}87,000(19 \%) \\
\text { Public Universities - 25,000 } \\
\text { Other Public Institutions - 22,000 } \\
\text { External Degree Programmes - 14,000 } \\
\text { Private Institutions - 26,000 }\end{array}$ \\
\hline Total & \begin{tabular}{l}
$450,000(100 \%)$ \\
\hline
\end{tabular} & $363,000(81 \%)$ \\
\hline
\end{tabular}

Source: Ministry of Higher Education, approximated to nearest thousand 


\section{Character development and the Educational System}

In adolescents, civic purpose depends on a firm intention that reflects deeply held moral and social values, a motivation to contribute to the broader society beyond the self and sustained action to accomplish what is intended. It has been shown by research that civic commitment declines as young people transit out of school [12]. Further, when adolescents leave a structured school environment, it deprives them of civic involvement, and this potentially affects their moral character and social responsibility [19]. After leaving school, if the adolescents are not engaged further in an academic or a civic organisation, it could lead to a decline in the application of favourable character strengths impacting their contribution to the development of the country. As shown in Table 2, approximately $80 \%$ of a birth cohort of a specific year in Sri Lanka is faced with this situation every year. The tertiary education enrolment rate in Sri Lanka is lower than in many other lower-middle income countries of the world [20]. Even the students who can be enrolled in higher education institutions in Sri Lanka are faced with unfavourable circumstances at times. A significant proportion of new entrants are faced with harassment by senior students, which is usually known as ragging [21]. Research shows that adolescents who were bullies have lower levels of moral character strengths as compared to young people not involved in bullying [22].

Schools could play a significant role in the character development of students. Specifically designed social-emotional and character development programmes are associated with the improvement of academic performance in lower income settings [23]. These programmes promote positive feelings, thoughts and actions and could be implemented through locally trained teachers and family members. Since the Sri Lankan culture is highly collectivistic and closely related to one's social identity, interventions that involve family members may likely to be more culturally appropriate and relevant to the real-life setting. In addition to school hours' activities to promote character development, other extra-curricular programmes such as scouting could be used to promote desirable character strengths among adolescents [24].

\section{Building Character and Corporal Punishment}

One of the critical aspects of management is ensuring further safety of the child at school and home. However, this has been a challenge due to the colonial era myths held by some educational, legal and health professionals of the country.

A recent study done in six districts in Sri Lanka involved close to 1000 school children. It found that more than $80 \%$ of students reported having experienced at least one episode of corporal punishment in the past school term [25]. Non-completion of homework, not adhering to the school dress code and love affairs were the most frequent reasons for being punished. The first reason is primarily driven by the exam-oriented educational system and the second and third reasons are related to the understandable psychosexual development stages of adolescents and their journey to find a meaningful sense of social belongingness. Furthermore, more than $70 \%$ of students reported having experienced at least one episode of psychological aggression in the past school term as well [25]. This occurs despite many decades of prevailing laws against cruelty to children of Sri Lanka. The legislature has been further strengthened by the circular number 12 issued by the 
Ministry of Education in 2016 which outlawed physical punishment and outlined methods of positive discipline in schools.

One of the significant barriers to stop cruelty in schools has been the belief that corporal punishment is part of the integral Sri Lankan child rearing practise. It is known that some consider banning corporal punishment is a embracement of the Western values [26]. However, there is evidence of ancient Sri Lankan kings who declared laws prohibiting any bodily harm, by way of punishment, to children. In contrast, during the British colonial rule in Sri Lanka, children caught flying a kite were ordered by law to be given lashes. With time, such colonial laws may have become the norm of disciplining children [27]. Furthermore, Sri Lanka being a Buddhist majority country, many parents and teachers, though aware of the character strengths of compassion and non-violence taught by Buddha, may not practice such non-violence in their daily child-rearing responsibilities. Lack of training in teachers of positive classroom management and structured behavioural techniques is a hindrance as well [28].

There are myths about corporal punishment that are not supported by research evidence; that such practices help to build character and are effective in the long run to control unacceptable behaviour, which is not supported by research evidence [28]. Rather than enhancing character strengths, corporal punishment is associated with significant psychological distress and complications such as aggression, delinquency, depression, and anxiety as shown by research from Sri Lanka and rest of the world [26, 29 30]. In relevance to other South Asian nations, a study from Pakistan has shown that corporal punishment is associated with academic deterioration in children compared to controls [31]. One other pro-corporal punishment argument is that it is a necessary measure as there is a low teacher to student ratio in Sri Lankan schools. However, a recent study shows that it is highly prevalent in urban, rural and estate sector schools despite drastic differences in the number of students per class [25]. Certain professionals are ambiguous towards physical punishment citing their own experience as children. They at times fail to understand the heterogeneous influence it has on children of different temperaments, the risk of physical abuse associated with it and the sociocultural evolution through the decades $[25,26,28]$.

A meta-analysis has shown that even though corporal punishment is associated with immediate compliance, it is associated with lower levels of moral internalisation and poor mental health [32]. Physical punishment could have long-term effects on character development and psychological health. Many studies from different parts of the world, conducted on large samples have shown that it is associated with later psychiatric ailments in adulthood such as depression, anxiety, lasting unhappiness, hopelessness and substance use issues [32-37]. Even when corporal disciplinary methods are used for extreme anti-social behaviours, longitudinal studies have shown that these behaviours persist despite these methods [38]. In considering these numerous studies from various sociocultural settings, it is quite evident that corporal punishment is not helpful to facilitate moral character growth in young persons. The child and adolescent mental health services of the country manage many school children experiencing psychological consequences related to being exposed to corporal punishment at schools. 


\section{Character Traits and Psychiatry}

There seems to be criticism from outside and within the speciality that psychiatry has failed to elevate the average levels of well-being in the general population. This is despite significant expenditure on psychotropic medications, physical therapies and psychotherapy manuals [39]. It is believed that the argued failure of psychiatry to improve well-being is the result of only focusing on psychopathology and the apparent neglect of employing methods that enhance character development, life satisfaction, spiritual growth and positive emotions [39]. Furthermore, the attention on specific diagnostic categories led to labelling patients and associated negative public attitudes [40]. However, the validity of categorical separation of symptomatology is doubtful and this at times, ignores the character and personality of the individual. Also, materialistic and overly simplistic reductionism leads to ignorance of spirituality and culturally relevant explanations for distress [39]. Regarding spirituality, research shows that individuals who practice their religion were more satisfied with their life than those who do not practice their religion and non-religious people. They were stronger in character strengths such as spirituality, hope, kindness, forgiveness, love and gratitude than non-practising and non-religious people [41]. It has been shown that subjective religiosity has a protective effect on attempted suicide among Sri Lankans [42].

It is found that character development could improve self-awareness, well-being and enhance happiness. Therapies that generate well-being in service users lead to more happiness in them and enhance character strengths that ultimately improve treatment adherence, minimise relapse and recurrence rates compared to psychotherapy or psychotropics alone [42-46]. The associated character traits include self-directedness, self-transcendence and cooperativeness [39]. Therefore, young people presenting with psychological distress need to be encouraged to engage in activities that enhance their character strengths such as spiritual, social and cultural programmes which would help to improve their overall well-being. This approach would help to achieve optimal outcomes through adolescent mental health services. Specialised mental health professionals are limited in child and adolescent services in Sri Lanka [47]. However, programmes could be developed based on local cultural values and spiritual beliefs to improve psychological well-being of Sri Lankan adolescents, that could be implemented through teachers.

\section{Application to the Sri Lankan Setting}

At present, there are only limited existing systemic character development programmes targeting Sri Lankan schools and universities. Most importantly, more than $80 \%$ leaving school would not have opportunities for standard higher education, and this group is likely not to obtain any regular guidance or mentorship to build character strengths. Child and Adolescent Mental Health Services in Sri Lanka need to look beyond mere psychopathology to promote the overall mental well-being of adolescents.

There is a need to initiate and facilitate inter-sectoral collaboration with child health and education services to implement character development programmes for adolescents in the country. The limited number of child mental health specialists is a major barrier to achieve this. Several provinces, including post-conflict areas in North and East of Sri 
Lanka, do not have specialised multi-disciplinary mental health teams for young people with child and adolescent psychiatrists [47-48]. Apart from this, the public health system does not routinely recruit clinical psychologists, and the education department has not recognised the need for school psychologists. Therefore, the character development programmes need to be school centred through trained teachers and supported by other services, including child mental health experts. The medical specialists are highly respected in the culture, and it is feasible to conduct training of trainers' programs for teachers working as school counsellors.

There is evidence from randomised controlled trials in the West that character development programmes could improve both mental and physical well-being of school students [49]. Many affluent countries have organised character-building programmes for adolescents. Post-doctoral training in a Western nation is mandatory for all Sri Lankan child and adolescent psychiatrists [47]. The experience gained from this advanced training needs to be culturally adapted and implemented in the country.

\section{Character Education}

Character education is a generic term for a wide range of approaches to provide moral learning and it needs to be culturally relevant [50]. Many Western psychotherapeutic approaches have core principles that align with Buddhist philosophy and other Eastern religious principles [51]. Likewise, we need to seek for character development programmes that may have been successfully implemented in other countries but adaptable to the local settings. To be effective, the character education programmes need to have several identified qualities, as shown in table $3[50,52]$.

Table 3: Principles of Effective Character Education

\section{Principles of Effective Character Education Programmes}

$>$ Promotes core ethical values as the basis of good character

$>$ Have a comprehensive understanding of the character

$>$ Respectful of cultural and religious beliefs of students and staff

$>$ Uses a proactive approach to character development

$>$ Create a caring environment at school

$>$ Include views of the stakeholders from different professional sectors

$>$ Provides opportunities for moral action

$>$ Implement a challenging syllabus, but a meaningful one to all learners

$>$ Encourage self-motivation among students

$>$ Engages the teachers as a learning and moral community

$>$ Engages families and local community members as partners in the character development

$>$ Evaluation of school staff's functioning as character educators and character strengths in students

Considering the Sri Lankan setting core values of Buddhism and other religions need to be incorporated in character development to ensure the longevity of programs.

Character development may have to be incorporated into postgraduate training in child 
and adolescent psychiatry as it is closely associated with the psychological well-being of adolescents.

Character education programmes could be implemented through local schools. The process could begin with development of character education tools. This could be done with local expertise in child and adolescent psychiatry, child psychology, and educational psychology. International collaborations could assist to find needed funding and improve the quality of the material. The developed tools for school children should be simple to be implemented by teachers. Training of teachers could be employed with the help of the Regional Director of Health Services and Zonal Education Director of the targeted region of Sri Lanka. The character development material could be modified through pilot projects to adapt to the local requirements and improve acceptability.

\section{Conclusion}

In conclusion, character is composed of various character strengths, and these are trainable personal characteristics. Purpose is the long-term, progressive intention to accomplish specific aims that are meaningful to the self and the broader world. Character strengths and purpose in adolescence is associated with academic achievements and long-term mental and physical well-being of a person. Identity crisis in adolescence is associated with moral character formation, developing a purpose and psychological wellbeing. Sri Lanka leads human development indices in the region and retention in secondary schooling is high. However, more than $80 \%$ of adolescents exit the educational system without a standard tertiary education and face a lack of opportunities to promote desirable character strengths.

Despite laws against child cruelty, corporal punishment and psychological aggression is highly prevalent in Sri Lankan schools and is counterproductive to long-term mental wellbeing and character development. Child and adolescent mental health expertise are limited in the country, and psychiatrists need to look beyond diagnostic categories to facilitate and support the character development of young Sri Lankans. Therefore, there is a need for school-based culturally relevant character development programmes and these need to be developed recognising moral, ethical, social and cultural values employing multi-sectoral collaboration. Incorporating character development to the postgraduate child and adolescent psychiatry training curriculum need to be considered.

\section{References}

1. Irwin T. Aristotle: Nicomachean Ethics. Indianapolis: Hackett. 1999. https://doi.org/10.1017/CBO9780511802058

2. Malin H, Liauw I, Damon W. Purpose and character development in early adolescence. Journal of youth and adolescence. 2017;46(6):1200-15. https://doi.org/10.1007/s10964-017-0642-3

3. Berkowitz MW. Moral and character education. APA educational psychology handbook. 2012; 2:247-64. https://doi.org/10.1037/13274-010

4. World Health Organisation [Internet]. Child and adolescent health and development. Adolescent health and development; 2017 [cited 2019]ul5]. 
Available from:

http://www.searo.who.int/entity/child_adolescent/topics/adolescent_health/en/

5. Peterson C, Seligman ME. Character strengths and virtues: A handbook and classification. Oxford University Press; 2004.

6. Harzer $C$, Ruch W. The relationships of character strengths with coping, workrelated stress, and job satisfaction. Front Psychol. 2015; 6:165. https://doi.org/10.3389/fpsyg.2015.00165

7. Wagner L, Ruch W. Good character at school: positive classroom behaviour mediates the link between character strengths and school achievement. Front Psychol. 2015; 6:610. https://doi.org/10.3389/fpsyg.2015.00610

8. Martínez-Martí ML, Ruch W. Character strengths and well-being across the lifespan: data from a representative sample of German-speaking adults living in Switzerland. Front Psychol. 2014; 5:1253. https://doi.org/10.3389/fpsyg.2014.01253

9. Bronk KC. A grounded theory of the development of noble youth purpose. Journal of Adolescent Research. 2012;27(1):78-109. https://doi.org/10.1177/0743558411412958

10. Damon W. The Path to Purpose: Helping Our Children Find Their Calling in Life. Simon and Schuster; 2008.

11. Keyes $C L$, Shmotkin D, Ryff CD. Optimizing well-being: The empirical encounter of two traditions. Journal of personality and social psychology. 2002;82(6):1007. https://doi.org/10.1037/0022-3514.82.6.1007

12. Malin $\mathrm{H}$, Han $\mathrm{H}$, Liauw I. Civic purpose in late adolescence: Factors that prevent a decline in civic engagement after high school. Dev Psychol. 2017;53(7):1384-1397. https://doi.org/10.1037/dev0000322

13. McAdams DP, Zapata-Gietl C. Three strands of identity development across the human life course: Reading Erik Erikson in full. The Oxford handbook of identity development. 2015:81-94.

14. Erikson EH. Identity and the life cycle. WW Norton \& Company; 1994.

15. Stiles DA, Gibbons JL, De Silva SS. Girls' relational self in Sri Lanka and the United States. The Journal of genetic psychology. 1996 Jun 1;157(2):191-203. https://doi.org/10.1080/00221325.1996.9914857

16. Bronk KC. The role of purpose in life in healthy identity formation: A grounded model. New Directions for Youth Development. 2011;2011(132):31-44. https://doi.org/10.1002/yd.426

17. Yeager DS, Henderson MD, Paunesku D, Walton GM, D'Mello S, Spitzer BJ, Duckworth AL. Boring but important: A self-transcendent purpose for learning fosters academic self-regulation. Journal of Personality and Social Psychology. 2014;107(4):559. https://doi.org/10.1037/a0037637

18. Chandradasa M, Rathnayake LC. Gender disparity as a threat to the mental wellbeing of young Sri Lankan women. BJPsych International. 2018:1-3. https://doi.org/10.1192/bji.2018.29

19. Flanagan C, Levine P. Civic engagement and the transition to adulthood. Future Child. 2010;20(1):159-79. https://doi.org/10.1353/foc.0.0043 
20. Dundar H, Millot B, Riboud M, Shojo M, Aturupane H, Goyal S, Raju D. Sri Lanka Education Sector Assessment: Achievements, Challenges, and Policy Options. The World Bank; 2017. https://doi.org/10.1596/978-1-4648-1052-7

21. Premadasa IG, Wanigasooriya NC, Thalib L, Ellepola AN. Harassment of newly admitted undergraduates by senior students in a Faculty of Dentistry in Sri Lanka. Med Teach. 2011;33(10): e556-63. https://doi.org/10.3109/0142159X.2011.600358

22. Hilliard LJ, Bowers EP, Greenman KN, Hershberg RM, Geldhof GJ, Glickman SA, Lerner JV, Lerner RM. Beyond the deficit model: bullying and trajectories of character virtues in adolescence. J Youth Adolesc. 2014;43(6):991-1003. https://doi.org/10.1007/s10964-014-0094-y

23. Bavarian N, Lewis KM, Dubois DL, Acock A, Vuchinich S, Silverthorn N, Snyder FJ, Day J, Ji P, Flay BR. Using social-emotional and character development to improve academic outcomes: a matched-pair, cluster-randomised controlled trial in lowincome, urban schools. J Sch Health. 2013;83(11):771-9. https://doi.org/10.1111/josh.12093

24. Lynch AD, Ferris KA, Burkhard B, Wang J, Hershberg RM, Lerner RM. Character Development within Youth Development Programs: Exploring Multiple Dimensions of Activity Involvement. Am J Community Psychol. 2016;57(1-2):73-86. https://doi.org/10.1002/ajcp.12035

25. De Silva H, Senarath U, de Zoysa P, Weerasinghe M. A Study on Child Disciplinary Methods Practiced in Schools in Sri Lanka [Internet]. National Child Protection Authority. 2017 [cited 20180ct3]. Available from: http://www.childprotection.gov.Ik/?page_id=2211

26. De Zoysa P, Newcombe PA, Rajapakse L. Consequences of parental corporal punishment on 12-year old children in the Colombo district. Ceylon Med J. 2008;53(1):7-9. https://doi.org/10.4038/cmj.v53i1.218

27. Moldrich D. Somewhere a child is crying. Colombo: Ceylon Printers Ltd. 1986:15-26.

28. Dubanoski RA, Inaba M, Gerkewicz K. Corporal punishment in schools: myths, problems and alternatives. Child Abuse Negl. 1983;7(3):271-8. https://doi.org/10.1016/0145-2134(83)90004-2

29. Gámez-Guadix M, Straus MA, Carrobles JA, Muñoz-Rivas MJ, Almendros C. Corporal punishment and long-term behaviour problems: the moderating role of positive parenting and psychological aggression. Psicothema. 2010;22(4):529-36.

30. Bryan JW, Freed FW. Corporal punishment: Normative data and sociological and psychological correlates in a community college population. J Youth Adolesc. 1982;11(2):77-87. https://doi.org/10.1007/BF01834705

31. Arif MS, Rafi MS. Effects of Corporal Punishment and Psychological Treatment on Students' Learning and Behaviour. Online Submission. 2007;3(2):171-80.

32. Gershoff ET. Corporal punishment by parents and associated child behaviours and experiences: a meta-analytic and theoretical review. Psychol Bull. 2002;128(4):53979. https://doi.org/10.1037/0033-2909.128.4.539

33. MacMillan HL, Boyle MH, Wong MY, Duku EK, Fleming JE, Walsh CA. Slapping and spanking in childhood and its association with lifetime prevalence of psychiatric 
disorders in a general population sample. Canadian Medical Association Journal. 1999;161(7):805-9.

34. Rodriguez CM. Parental discipline and abuse potential effects on child depression, anxiety, and attributions. Journal of Marriage and Family. 2003;65(4):809-17. https://doi.org/10.1111/j.1741-3737.2003.00809.x

35. Javo C, Rønning JA, Heyerdahl S, Rudmin FW. Parenting correlates of child behaviour problems in a multi-ethnic community sample of preschool children in northern Norway. European child \& adolescent psychiatry. 2004;13(1):8-18. https://doi.org/10.1007/s00787-004-0349-3

36. Turner HA, Muller PA. Long-term effects of child corporal punishment on depressive symptoms in young adults: Potential moderators and mediators. Journal of Family issues. 2004;25(6):761-82. https://doi.org/10.1177/0192513X03258313

37. Afifi TO, Brownridge DA, Cox BJ, Sareen J. Physical punishment, childhood abuse and psychiatric disorders. Child abuse \& neglect. 2006;30(10):1093-103. https://doi.org/10.1016/j.chiabu.2006.04.006

38. Grogan-Kaylor A. Corporal punishment and the growth trajectory of children's antisocial behaviour. Child Maltreat. 2005;10(3):283-92. https://doi.org/10.1177/1077559505277803

39. Cloninger CR. The science of well-being: an integrated approach to mental health and its disorders. World Psychiatry. 2006;5(2):71-6.

40. Angermeyer MC, Matschinger $\mathrm{H}$. The stigma of mental illness: effects of labelling on public attitudes towards people with mental disorder. Acta Psychiatr Scand. 2003;108(4):304-9. https://doi.org/10.1034/j.1600-0447.2003.00150.x

41. Berthold A, Ruch W. Satisfaction with life and character strengths of non-religious and religious people: it is practising one's religion that makes the difference. Front Psychol. 2014; 5:876. https://doi.org/10.3389/fpsyg.2014.00876

42. Hasler G. Well-Being: An Important Concept for Psychotherapy and Psychiatric Neuroscience. Psychother Psychosom. 2016;85(5):255-61. https://doi.org/10.1159/000447268

43. Fava GA. Well-being therapy: Treatment manual and clinical applications. Karger Medical and Scientific Publishers; 2016. https://doi.org/10.1159/isbn.978-3-318-05822-2

44. Farquharson L, MacLeod AK. A brief goal-setting and planning intervention to improve well-being for people with psychiatric disorders. Psychother Psychosom. 2014;83(2):122-4. https://doi.org/10.1159/000356332

45. Gaiswinkler L, Unterrainer HF, Fink A, Kapfhammer HP. [The relationship between Yoga Immersion, psychological well-being and psychiatric symptoms]. Neuropsychiatr. 2015;29(1):29-35. https://doi.org/10.1007/s40211-015-0139-9

46. Fukui S, Starnino VR, Nelson-Becker HB. Spiritual well-being of people with psychiatric disabilities: the role of religious attendance, social network size and sense of control. Community Ment Health J. 2012;48(2):202-11. https://doi.org/10.1007/s10597-011-9375-z 
47. Chandradasa M, Champika L. Subspecialisation in postgraduate psychiatry and implications for a resource-limited specialised child and adolescent mental health service. Academic Psychiatry. 2019 Feb 15;43(1):135-9.

https://doi.org/10.1007/s40596-018-0920-8

48. Chandradasa M, Kuruppuarachchi KALA. Child and youth mental health in post-war Sri Lanka. BJPsych Int. 2017;14(2):36-37. https://doi.org/10.1192/S2056474000001756

49. Bavarian N, Lewis KM, Acock A, DuBois DL, Yan Z, Vuchinich S, Silverthorn N, Day J, Flay BR. Effects of a School-Based Social-Emotional and Character Development Program on Health Behaviours: A Matched-Pair, Cluster-Randomized Controlled Trial. J Prim Prev. 2016;37(1):87-105. https://doi.org/10.1007/s10935-016-0417-8

50. Nucci L, Krettenauer T, Narváez D, editors. Handbook of Moral and Character Education. Routledge; 2014.

51. Chandradasa M, Kuruppuarachchi KA. Confluence of western psychotherapy and religious teachings in mental healthcare of an Asian Buddhist community: Sri Lanka. Journal of Religion and Health. 2018 Jul 27:1-6. https://doi.org/10.1007/s10943-018-0674-3

52. Lickona T, Schaps E, Lewis C. CEP's Eleven Principles of Effective Character Education. Character Education Partnership. 2007. 